\title{
Levels of Processing and Producing Conventional Metaphors by English Foreign Language Learners in Written Language
}

\author{
Hala Mohamed Osman Salih \\ Banan Hassan Alhajaji \\ Najat Ahmed Busabaa \\ Hanan Abdullah Nagi \\ English Language Department \\ Faculty of Languages and Translation \\ King Khalid University \\ Kingdom of Saudi Arabia
}

\begin{abstract}
This study attempts to investigate EFL learners' ability to process and produce metaphorical expressions in English and whether these expressions are conceptualized in their mother tongue, Arabic. One hundred and twenty five Saudi female EFL students participated in the study. A questionnaire and a writing task were used as instruments to collect the data of the study. Thirty English metaphorical expressions of happiness, sadness, anger, fear and love were first distributed to 125 EFL learners to test their ability to process and understand metaphors in English. Then a writing task of five paragraphs on daily experiences of emotions was provided to examine the extent of learners' productivity of metaphorical expressions. The study concludes that EFL learners have the ability to process and produce English metaphors but in variable rates. The most frequent metaphorical expressions are metaphors of happiness, sadness and love. Fear and anger metaphors were significantly lower.
\end{abstract}

Keywords: Metaphors, expressions, processing, producing, ability, Saudi female students, emotion, cultural factors, written language, levels

\section{Introduction}

What is a metaphor? Most of us think of a metaphor as a device used in songs or poems only, and that it has nothing to do with our everyday life. In fact, metaphor is used in everyday life to describe thoughts, emotions or experience. Metaphor is a cognitive process whereby one empirical domain is partially mapped and projected to another different empirical domain (Barcelona, 2000). Most definitions of metaphor encompass an understanding or comprehension of two or more conceptual domains. To Lanham (1968), a metaphor is the method of translating a term from its literal meaning into a phrase that is not necessarily true but equivalent. That happens when a notion is borrowed from its familiar semantic domain and applied to another unusual semantic domain (Heath, 2003). To Richard (1936), metaphors are made up of three elements: tenor, vehicle and ground. Lakoff and Johnson (1980) named the first two elements target and source, which have become common terms in the development of the cognitive linguistics field, and they are used in this study. The target comes first and it is the thing being compared and being conveyed. The source is the latter and it is the thing to which something has been compared. These two elements have become general terms in the development of the cognitive linguistics field. The ground of metaphor is the actual motivation (e.g. analogy or similarity) for using the source. Thus, to extend the metaphor, the source conveys the target over the ground. In the metaphorical expression "ship of state" the target here is "state" while the source is the surface idea of "ship" (Heath, 2003).

Metaphor has been studied for nearly 2000 years within the discipline recognised as rhetoric. This discipline emerged from Ancient Greece and concentrated on functional instruction on how to stimulate audiences through rhetorical tools. It is one of these tools, which were known as tropes by rhetoricians. Furthermore, it has a central significance as it was called the master trope. Generally speaking, metaphor was derived from the schematic style A is B, such as in Achilles is a lion. Where the comparison of two categories is the norm; however, this comparison is not explicitly clear, as the comparison in a simile is openly indicated by using as or like, such as in "Achilles is as brave as a lion" or "He is brave like a lion"(Evans \& Green, 2006). To Roberts and Kreuz (1994) metaphors are a prevalent part of everyday written and spoken speech. Similarly, metaphors enable us to own a larger impact on the readers. 
With them, we will convey a concept more persuasively than with a standard statement. Although there are overemphasize in metaphorical expressions, they are just overstated to paint a distinctive picture or offer a significant expression.In this study the researchers are intended to investigate the processing and producing of metaphors by Saudi female EFL learners in English and whether these metaphors are also conceptualized in their mother tongue, Arabic.

\subsection{Aim of the Study}

The aim of this study is to investigate the Saudi female EFL learners' ability to process the conventional metaphorical expressions that are given to them, and their ability to produce metaphors to describe their emotions on happiness, sadness, anger, fear, and love.

\subsection{Questions of the Study}

The study attempts to answer the following questions:

1- To what extent do Saudi female EFL learners process metaphorical expressions given to them?

2- What are the most emotional metaphorical expressions processed by Saudi female EFL learners?

3- To what extent do Saudi female EFL learners have the ability to produce conventional metaphorical expressions in their written language?

4- What are the most patterns of metaphorical expressions produced by Saudi female EFL learners in their written language?

\subsection{Significance of the Study}

The study analyzes students' differences in the way they processed conventional metaphorical expressions and the choice they made in producing these conventional metaphorical expressions from a linguistic perspective. This might contribute to the Saudi studies on linguistics and ELT as well.

\subsection{Limitation of the Study}

The present study is confined to investigating certain particular group of students. These are Saudi female EFL learners at Faculty of Languages\& Translation, King Khalid University, Abha. Other students will be out of the scope of this study and so, the results might be limited to this group of participants.

\section{Literature Review}

Metaphors have been recognized as rhetorical devices that compare two seemingly different objects. This occurs when certain distinct attributes of one object are grounded in the other, thus describing the latter with the qualities intrinsic to the former. Metaphoric devices use is considered as a vital element and a part of everyday ordinary speech. Cognitively, Lakoff and Johnson (1980) and Kövecses (2010) argue that language serves as an evidence for the existence of conceptual metaphors. According to Lakoff and Johnson (2003), metaphors are viewed as a cognitive process, where a link between two conceptual domains, i.e. the source and target domains, is established. Moreover, metaphorical orientations are not arbitrary. For instance, "I'm feeling up", spirits rose have basis in our physical and cultural experience to show happiness, while "I'm feeling down", "I'm depressed", "He's really low these days" show sadness. Metaphors have played a significant role in human life throughout history. This specific role enhances the expansion of metaphor use as a phenomenon. The youth and the old use metaphors to express thought or emotions or experience in recent or ancient days. It is of no doubt that when a figurative expression used by a person overtly to mean something, whereas implicitly it implies something else, it is convenient to say that the device used is a metaphor Katz (1996). However, it varies significantly according to the cultures. Recent studies encourage renewed interest in metaphor study. Charteris-Black (2002) investigates figurative expressions in English and Malay in terms of the similarities and differences between the two languages. The study also attempts to anticipate the difficulties encountered by Malay EFL learners with regard to figurative expressions. The results show that students faced difficulties with certain types of linguistic expression that differed from Malay in terms of conceptual and cultural basis. Shokouhi and Isazadeh (2009) explore the means by which Iranian EFL learners can acquire and use conceptual and image metaphors in English. 60 junior students of high proficiency level in English participated in the study. After 10 sessions of instruction; students were acquainted with 40 metaphors of both types, namely conceptual and image metaphors. The researchers used a 30item completion test that was divided into two parts; word - given and recognition tests. The results demonstrated no significant difference in the rate of acquiring the two types. However, based on the results, the two researchers reported that cultural awareness of the figurative expressions of the target language may contribute considerably to the development of communicative competence, in addition to other language skills. In her study, Zibin (2016) explores the ability of Jordanian learners of English as a foreign language learners to produce English metaphorical expressions, and whether participants' knowledge of conceptual and linguistic metaphors of their mother tongue Jordanian have an influence on the production of metaphorical expressions. 
The results indicate that the participants exhibited a general capacity to produce metaphorical expressions that are similar in meaning to the ones required on the test, utilizing their first language conceptual and linguistic knowledge. A good command of English collocational knowledge and familiarity with the concept of partial synonymy, and continuous exposure to the figurative expressions in real-life English proves to be an influential factor to comprehend the metaphors involved. On the other hand, Đonan Ha (2015) investigates students' use of metaphorical language from product and process perspectives. The results show that learners had low awareness of the metaphorical nature of the language they used, and that the underlying thoughts behind their metaphorical language use involved more non metaphoric than metaphoric thinking.

In his study, Al Jumah (2007) compares and contrasts the usage and understanding of English and Arabic metaphors. His study attempts to reveal how students interpret metaphors in both their native and acquired languages and if their mother tongue and culture affect their metaphorical thinking. Results of the study revealed parallels and divergences in Arabic and English metaphorical usage and comprehension by Arab students.

\section{Methodology}

\subsection{Participants}

The participants were Level 7 Saudi female EFL learners studying English Language and Translation at the Faculty of Languages and Translation at King Khalid University, Abha., Saudi Arabia. Their age was between 22-23 years old. They were at the final stage of their BA in English Language and Translation.

\subsection{Procedure}

A number of English expressions used in conceptualizing happiness, sadness, anger, fear and love in English were illustrated in a form of a questionnaire of 30 items compiled by the researchers and had been distributed to 125 participants. The items of the questionnaire have been divided equally. 6 items have been introduced for each emotion. The items were distributed according to the degree of difficulty; from the most to the least randomly. The expressions and items of the questionnaire were collected from "A Dictionary of American Idioms, compiled by Makkai and Roget's Thesaurus (as cited in Vosepoor,1993, p.28-29),to test the participants' ability to process metaphors in English. The collected items were examined thoroughly to ensure their conceptual bases and linguistic expressions in English. Finally, the items were put in a multiple choice so that they were used as clues to indicate one of the five topics in question and the students have to choose. To investigate the ability, the participants had in producing metaphorical expressions, the students were asked to write a paragraph of no more than 100 words in five topics using metaphorical expressions to express their feelings and describe their emotions on happiness, sadness, anger, fear and love in English. With the aim to collect authentic written data (Granger, 2002, p.8), written by the students themselves, the task was set to be an in-class writing task. The topics the researchers asked the participants to write on are as follows:

1-Describe the best moment that gives you all the happiness in the life. (happiness)

2-Describe a very hard moment that gives you the feeling of sadness. (sadness)

3 -Describe your feeling in a very bad moment or situation. (anger)

4-Describe the moment you feel scared of something in a particular day. (fear)

5-Express your emotions when you love someone so much. (love)

\subsection{Data Analysis}

The analysis of data was carried out by analyzing the metaphors individually following Lakoff and Johnson's (1980) Conceptual Metaphor Theory analysis in addition to Köveceses'(2003) theory as the model of linguistically metaphorical expressions. The collected expressions were first grouped into general source domains "Up and Down" for (happiness, sadness, anger, fear and love). Looking for any use of metaphorical expressions, the researchers described the expression's functioning in its context. Then they were analyzed qualitatively and quantitatively. Meanwhile, the researchers put it clear that the English conceptual metaphorical expressions understood and produced by EFL learners for describing emotions were observed in the Arabic language as well.

\section{Analysis and Findings}

The analysis and findings of the study are of two folds: the extent to which EFL students' process apply these metaphorical expressions in their writing. First the researchers analyzed the students' ability to process metaphorical expressions. To what extent they process the items given to them in the questionnaire is considered as a pre-test to enhance their oriented recognition of the metaphorical devices. Then the researchers analyzed the students' written paragraphs to uncover the metaphorical use, if there is any, in their writing.

\subsection{Saudi Female EFL Students' Process of Metaphorical Expressions}




\subsubsection{To What Extent Do Saudi Female EFL Learners Process Conventional Metaphorical Expressions?}

30 items have been given to the students to test their ability to process metaphorical expressions. Figure 1 provides the reader with a summary of the frequencies of accurate responses of the students to the 30 items. As shown, figure (1) indicates that Saudi female EFL learners have a positive response towards processing conventional metaphorical expressions given to them. Out of 125 of the students, 93 have recognized happiness, 67 have the ability to process sadness, 59 responded to anger, 53 responses for fear, and 62 responded to love.

\subsubsection{What are the Most Emotional Metaphorical Expressions Processed by Saudi Female EFL Learners?}

As shown, table (1) reports the means and standard deviations of the correct responses of each emotion. They are happiness, sadness, anger, fear, and love. In accordance to the mean and the percentages listed in table 1, happiness is the most emotional metaphorical expression processed by Saudi female EFL learners as the standard deviation (SD) is (0.055). $76 \%$ of the students have been positively responded. The highest responses were for item 15 " He is sunny", which is classified by the researchers as medium with total percentage of $87.2 \%$, compared with $63.2 \%$ for item 4 " $\mathrm{He}$ is in high spirits", which is classified by the researchers as easy as the least responded item. However, students negatively responded to the metaphors that were associated with fear (43\%).The highest responses were for item 23 " He is shaking in his shoes", which is classified by the researchers as easy with total percentage of $60.8 \%$, compared with $21.6 \%$ for item 27 " He gives her the creeps" which is classified by the researchers as difficult. The second emotion is sadness $(54 \%$, with $\mathrm{SD}=0.060)$. The highest responses were for item 2 "It is breaking his heart", which is classified by the researchers as easy with total percentage of $86.4 \%$, compared with $21.6 \%$ for item 25 "He is hitting rock bottom", which is classified by the researchers as difficult. Love comes in the third position (51\% with $\mathrm{SD}=0.081$ ).The highest responses were for item 26 "He has a sweet heart", which is classified by the researchers as easy with total percentage of $82.4 \%$, compared with $8 \%$ for item 7 "He is being swept of his feet", which is classified by the researchers as difficult. Then, comes the emotion of anger in the fourth position with $47 \%$ and, SD=0.024. The highest responses were for item 9 "He is boiling", which is classified by the researchers as easy with total percentage of $67.2 \%$, compared with $24 \%$ for item 22 "He is jumping down her throat", which is classified by the researchers as difficult. Fear comes as the least emotion of metaphors processed by Saudi female EFL learners 43\% with SD =0.034. By analyzing the data, it is revealed that most students identified metaphorical expressions, but in varying proportions, that happiness is the most frequent followed by sadness and love then anger and the least frequent was fear.

\subsection{Saudi Female EFL Students' Production of Metaphorical Expressions}

\subsubsection{To What Extent Do Saudi Female EFL Learners Have the Ability to Produce Conventional Metaphorical Expressions?}

The second part of the study was conducted to investigate students' ability to produce metaphorical expressions in the written form given to them. However, only 103 participants wrote 5 paragraphs expressing an experience they passed through to express happiness, sadness, anger, fear and love respectively. The results of the study show that Saudi female EFL learners have a positive response towards producing conventional metaphorical expressions. The participants were able to produce metaphors in their writing with no significant difference. It was indicated that 84 metaphors had been written on happiness, 83 on sadness, 60 on anger, 83 on love; however, fear was the least in number (45), when comparing with the production of other metaphorical expressions. This has been illustrated in figure (2):

4.2.2. What are the Most Patterns of Metaphorical Expressions Produced by Saudi Female EFL Learners in their Written Language?

It was found that Saudi female EFL learners have the ability to produce metaphorical expressions of happiness $(81.55 \%)$ more than any other emotions. Sadness and love $(80.58 \%)$ are equal in range, and then anger (58.25\%). The least metaphor produced by the students was fear with a total percentage of $43.69 \%$ as shown in figure (2). Even though the participants' responses on happiness were the highest compared to the other types, their performance is still low.

\section{Discussion}

\subsection{Processing of Metaphorical Expressions by SaudiFemale EFL Learners}

Some current researchers argue that the study of emotion concepts is an important issue for the process of cognition. According to Oatley and Jenkins (1996),"emotions are not extras but the very center of human life" (p122). Lakoff (1987), on the other hand, claims that emotions have an extremely complex structure, which gives rise to a wide variety of non-trivial inferences. 
The researchers-on their focus on the emotional metaphors- convincingly confirm that the emotional language which is used by various cultures is broadly metaphorical and the concepts of emotions that people use around the world in different cultures are metaphorically understood (Kövecses, 2002, 2003, 2005, 2006, 2008; Lakoff, 1987; Barcelona, 1986). A careful glance at Table 1 and Figures, 1 and 2, one will recognize that Saudi female EFL learners have the ability to process and produce conventional metaphors to express their emotions. Despite the participants' achievement in the recognition of the production of metaphors as shown in table (1) and figure (2) respectively, it is unquestionably clear that there were statistically significant differences between emotions (Happiness, 76\%), and (sadness, 54\%), 3 (anger,47\%), 5 (love, 51\%), and4 ( fear, 43\%).On the other hand, even though, there were statistical differences between the students' answers of processing these expressions, the students have facilitated their conceptual and linguistic knowledge to be able to process metaphors.

\subsection{Production of Metaphorical Expressions by Saudi Female EFL Learners}

\subsubsection{Happiness}

To Lakoff and Johnson (1980), many languages may share certain conceptual metaphors, particularly emotional ones. Happiness, for instance, as a "conceptual metaphor" is the most ultimate universal concept. Kovecses (1991b), points out that there are a large number of conceptual metaphors based on happiness in English. Conceptual metaphors reflect knowledge and reveal a view of the world as constructed by a specific culture. An analysis of conceptual metaphors contributes to the understanding of the culture itself. Three of those conceptual metaphors stand out of importance; "HAPPINESS IS UP","HAPPINESS IS LIGHT" and "HAPPINESS IS FLUID". These metaphorical expressions tend to be universal because they are based on the common bodily experience which can be shared by all human beings (Chen, 2010). Moreover, following the metaphor "HAPPY IS UP", the source domain is happy while the target domain is up. By analyzing the findings, $81.55 \%$ EFL learners are able to understand and produce common English metaphorical expressions based on the metaphor "HAPPINESS IS UP" such as "I was flying high", "I was walking on cloud nine", and "there is a butterfly goes out of my heart". Furthermore, happiness can be a domain from moderate satisfaction to strong euphoria;"I was in heaven" makes one feel the expression.

\subsubsection{Sadness}

Based on the metaphor "SAD IS DOWN", $80.58 \%$ of the learners responded positively. The source domain, here, is comprised by the spatial "DOWN" (Lakoff \& Johnson, 1980). The source is the emotion of sadness, while the target is feeling down. This conceptual metaphor is very common in English and in Arabic as well. Nevertheless, in most expressions that the researchers have analyzed, metaphors such as "I am quite down", "the blood is running down" and "I feel very down" are very common in the learners' use of metaphors. Other examples based on the "SADNESS IS DARK", metaphor, where the metaphorical expressions which are based on sadness are related to the color black, such as "I've been in a dark world", "life is black", "my life is black", and "I am in the dark mood" are also common among the learners' ability to produce metaphors. Kovecses (2000) points they are common metaphors and most people who feel sad prefer dark to light places. That is why we can see them in English and Arabic Languages.

\subsubsection{Anger}

Anger is conceptualized in terms of temperature. If people feel angry, they get a very high temperature and they will explode. Lakoff (1987) described in the folk theory of the physical effects when a person feels angry, it leads to body heat, blood pressure and confusion with accurate perception. For example, "I was boiling", "my blood was boiling", "I exploded", "there was an explosion in my heart", "I almost exploded" and "anger is a fire" are metaphors associated with fire and heat; "ANGER IS FIRE" and "ANGER IS HEAT". According to data analysis in the current study, the percentage of producing the anger emotion is (58.25\%). It is obvious then that EFL Saudi students are not proficient to produce and process anger. The inability of achieving proficiency in producing such metaphors is because of lack of exposing the students practically to these forms in the target language as they exist in both languages. This result confirms the findings presented in Charteris- Black (2002). Both students, the Saudi and Malay faced difficulties with certain types of metaphorical expressions. However, the reasons are completely different. In the Malay case it is because they are different from their conceptual and cultural basis but in Saudi case, the reason may be attributed to pedagogical reasons. On the other hand, the results can be explained in terms that learners had low awareness of the metaphorical nature of the language they used (Đonan Ha 2015).

In most cases, metaphors that express emotions are quite frequent because in almost cases they emotions are integrated within the in humans' lives. [However], the time it is not used frequently in everyday experiences, then its frequency will not be high (Zibin 2016).

\subsubsection{Fear}


According to Köveces (1990), the metaphor of fear is conceptualized by various source domains in English. Based on the analysis of the emotional metaphorical expressions, EFL learners faced difficulties with the recognition of certain types. $43.69 \%$ were capable to produce the metaphorical expressions related to the fear emotion. It is the least ever percentage Saudi EFL learners have experienced. This can be grounded in the divergences in Arabic and English metaphorical usage and comprehension by Arab students (Al Jumah, 2007).In this case, learning figurative expressions of the target language may contribute considerably to the development of communicative competence, in addition to other language skills (Shokouhi and Isazadeh 2009). The least difficult, "I had frozen", "I'll jump out of my skin", and "I was shaking in my shoes" are the most common expressions repeated in their writing.

\subsubsection{Love}

Love concept exists in English and Arabic languages as well. "LOVE IS A JOURNEY" metaphor has been excessively discussed by many scholars. The conceptual structure of "JOURNEY" is the source domain, while the target domain is "LOVE" (Lakoff \& Johnson, 1980; Kövecses, 2002). According to the results, 80.58\% of EFL learners show the ability to produce metaphors on love;"I stuck on him", "he is the apple of my eye", "I want to bring the sun if I love him", and "my heart was flying", "life is happy and pink". The higher percentage in the production of love metaphor shows learners' conceptual knowledge of metaphors in Arabic and English. Such result goes with Zibin's (2016) finding which indicates that the learners' general ability to produce metaphorical expressions because they activate their mother tongue conceptual and linguistic knowledge.

\section{Conclusion}

Since the publication of Lakoff and Johnson's (1980), "Metaphor We Live BY", conceptual metaphors have been one of the main topics in cognitive linguistics. In this study, the researchers investigate the ability of Saudi female EFL learners to process and produce English metaphorical expressions. Conceptual metaphors shape the different ways the students think on metaphors and so they reflect them in their writing. With the analysis of metaphors processed and produced by EFL learners, cognitive conceptual approach is used by the researchers to analyze the writing of the students quantitatively and qualitatively to estimate their ability to produce metaphors and to show how they are used. The researchers used two main instruments; the questionnaire as a pre-test to examine the ability of the students to achieve cognitive knowledge and so to be able to comprehend metaphorical expressions. The second is asking the students to write on five typical emotions they experience in their everyday life. The two types of instruments used to facilitate this knowledge into a form of performance. Metaphorical language is significantly related to language proficiency and writing proficiency in particular. The results indicate that the percentages of using metaphors for processing and producing metaphors are varied. However, the most frequent metaphorical expressions are those metaphors of happiness, sadness, love, fear and anger metaphors were significantly lower than happiness sadness, and love. The reasons why some are highly used and produced; others are not can be explained in terms of that many languages may share certain conceptual metaphors, happiness, for instance is frequently used in both languages in everyday speech. Lack of cultural background knowledge, less frequent use of metaphors such as anger and fear in daily life, lack of exposure to the metaphorical expressions used in the target language, in addition to lack of awareness of the importance of teaching students the metaphorical expressions may cause the low scores of the students to process and produce metaphors of anger and fear. For future researches, it is highly recommended for pedagogical reasons; teachers should focus on teaching written metaphorical expressions to learners, monitoring and encouraging them to develop this skill.

\section{References}

Al Jumah, F. H., (2007). A Comparative study of metaphor in Arabic and English General Business Writing with teaching implications. Theses and Dissertations 996. http://knowledge.library.iup.edu/etd/996

Barcelona, A., (1986). On the concept of depression in American English: A cognitive approach. Revista Canaria de Estudios Ingleses, 12, 7-33.

Barcelona, A., (2000). Metaphor and Metonymy at the Crossroads: A Cognitive Perspective. Berlin: Mouton de Gruyter.

Charteris-Black, J., (2002). Second language figurative proficiency: A comparative study of Malay and English. Applied Linguistics, 23,(1),104-133.

Chen, P., (2010). A cognitive study of happiness metaphors in English and Chinese idioms. Asian Culture and History, 2, 172-175.

ĐOAN HA., H THI., (2015). Metaphorical languages in second language learners' essays: Products and processes. A thesis submitted to Victoria University of Wellington in fulfillment of the requirements for the degree of Doctor of Philosophy in Applied Linguistics. 
Evan, V., \& Green, M.,(2006). Cognitive Linguistics: An Introduction. Edinburgh: Edinburgh University Press.

Granger, S., (2002).A bird's eye view of learner corpus research. In Computer Learners corpora, Second Language Acquisition and Foreign Language Teaching, S Granger, S. Hung \& S. Petch-Tyson (eds.)3-33. Amsterdam: John Benjamines.

Heath, P., (2003) Metaphor. In: J. McAuliffe, ed. Encyclopaedia of_Qur'an. Boston: Brill. pp. 384-388.

Katz, A., (1996). Experimental Psycholinguistics and Figurative Language: Circa 1995. Metaphor and Symbolic Activity, 11(1), 17-37.

Kovecses, Z., (1990). Emotion concepts. Berlin and New York: Springer- Verlag. http://dx.doi.org/10.1007/978-14612-3312-1.

Kövecses, Z., (1991b). Happiness: A definitional effort. Metaphor and Symbolic Activity, 6, 29-46.

Kovecses, Z. (2000). Metaphor and emotion: Language, culture, and body in human feeling. New York: Cambridge University Press.

Kövecses, Z. (2002). Metaphor: A practical introduction. Oxford and New York: Oxford University Press.

Kövecses, Z. (2003). The Scope of Metaphor in Barcelona, A. (ed.), Metaphor and Metonymy at the Crossroads: A Cognitive Perspective. Berlin: Mouton de Gruyter, 79-92.

Kövecses, Z. (2005). Metaphor in culture: Universality and variation. New York and Cambridge: Cambridge University Press. 157.

Kövecses, Z. (2006). Embodiment, Experiential Focus, and Diachronic Change in Metaphor. Paper presented at the 2005 Symposium on New Approaches in English Historical Lexis. In: R.W. McConchie, O. Timofeeva, H. Tissari\& T. Säily (eds.)

Kövecses, Z. (2008). Universality and Variation in the Use of Metaphor. In: N.-L. Johannesson, \& D.C. Minugh (eds.), Selected Papers from the 2006 and 2007 Stockholm Metaphor Festivals. Stockholm: Stockholm University, 51-74. http://shu.bg/tadmin/upload/storage/161.pdf

Kövecses, Z. (2010). Metaphor: A practical introduction. (2d edition). New york: Oxford University Press. https://www.academia.edu/8497194/K\%C3\%B6vecses_Z._2010_Metaphor_A_Practical Introduction._2nd_Ed._New_York_Oxford_University_Press

Lakoff, G. (1987). Women, fire and dangerous things: What categories reveal about the mind. Chicago: University of Chicago Press.

Lakoff, G \& Johnson, M. (1980).Metaphors we live by. Chicago: University of Chicago Press.

Lakoff, G.,\& Johnson, M., (2003).Metaphors we live by. London: The university of Chicago press.

Lanham, R. A., (1968). A hand list of rhetorical terms: A guide for students of English literature. Berkeley: University of California Press.

Oatley, K. \& Jenkins, J., (1996).Understanding emotions. Malden, M.A: Blackwell.

Richard, P.(1936).The philosophy of Rhetoric. Oxford: Oxford University Press.

Roberts, R. \&Kreuz, R., (1994). Why do people use figurative language? Psychological Science, 5, pp. 159-163.

Shokouhi, H.,\&Isazadeh, M.(2009). The effect of teaching conceptual and image metaphors to EFL learners, Open Applied Linguistic Journal, 2, 22-31.

Verspoor, C M. (1993).What are the characteristics of emotional metaphors? Retrived from: http//: compbio.ucdenver.edu > Verspoor > Education_files > met-thesis

Zibin, A. (2016) On the production of metaphors and metonymies by Jordanian EFL learners: Acquisition and implications. Topics in Linguistics, 17(2),41-58 
Appendix of figures and Tables

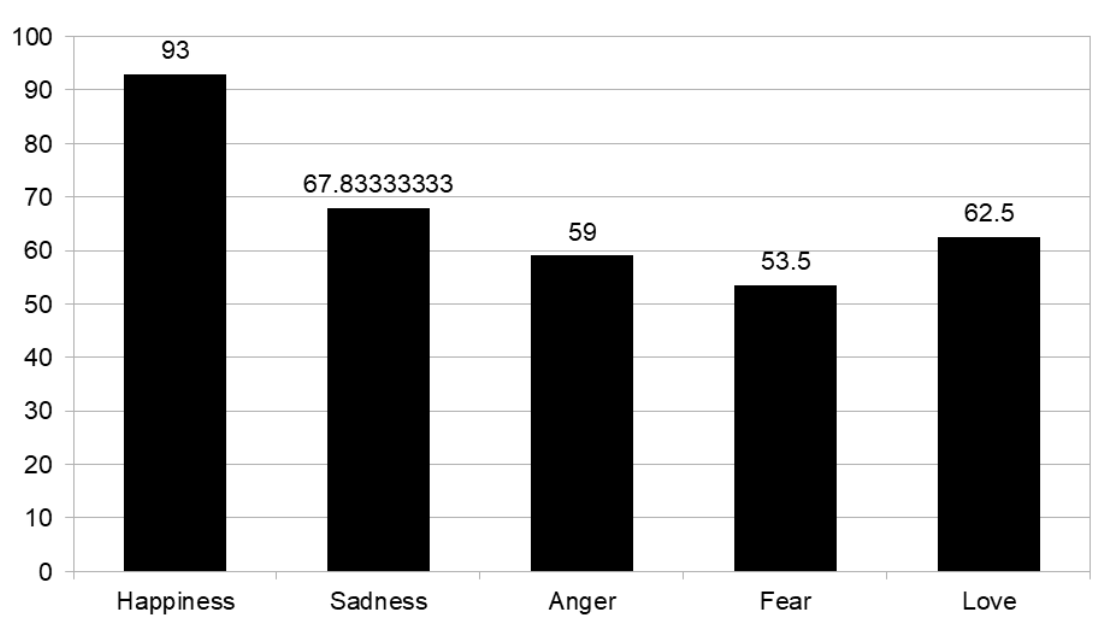

Figure (1): Frequency of Processing Metaphorical Expressions

Table (1): Means and Standard Deviation of the Students' Responses

\begin{tabular}{|l|l|l|l|l|l|}
\cline { 2 - 6 } \multicolumn{1}{c|}{} & Happiness & Sadness & Anger & Fear & Love \\
\hline $\begin{array}{l}\text { Mean of the students' Positive } \\
\text { responses }\end{array}$ & $76 \%$ & $54 \%$ & $47 \%$ & $43 \%$ & $51 \%$ \\
\hline Standard Deviation & 0.055 & 0.060 & 0.024 & $\mathbf{0 . 0 3 4}$ & $\mathbf{0 . 0 8 1}$ \\
\hline
\end{tabular}

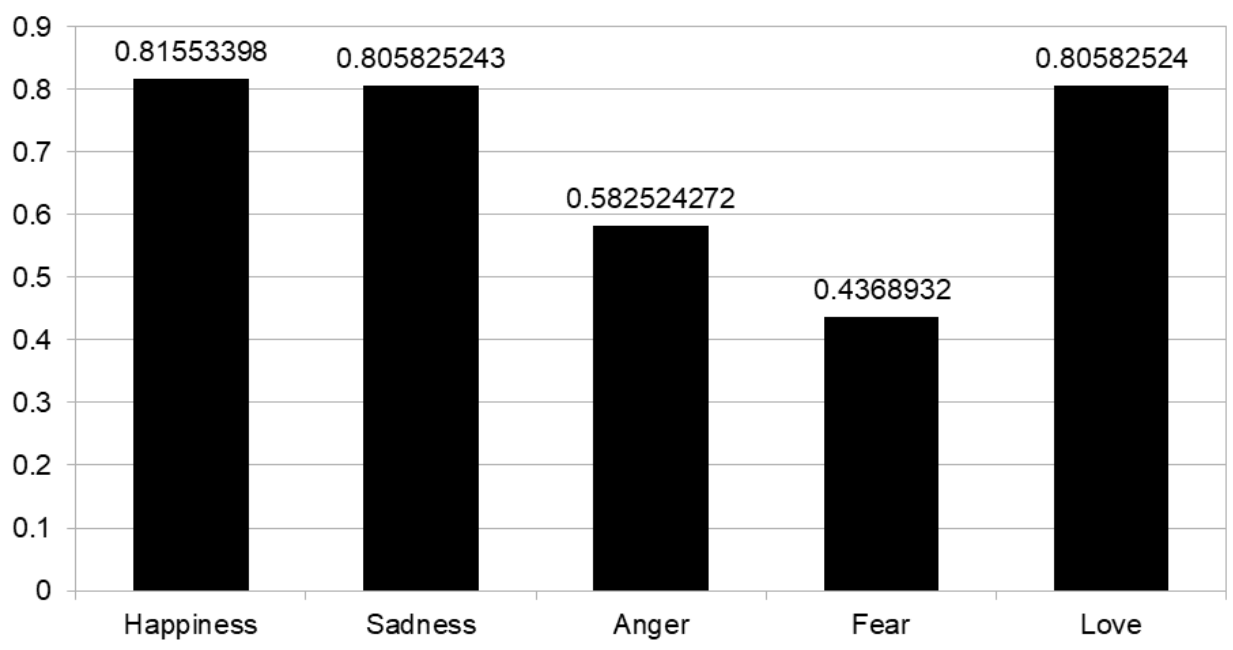

Figure (2): Means of the Students' Productivity of Metaphorical Expressions 